\title{
THE EFFECT OF DRY GRINDING ON ANTIGORITE FROM MULHACEN, SPAIN
}

\author{
A. DRIEF AND F. NiETo \\ Departamento de Mineralogía y Petrología, Instituto Andaluz de Ciencias de la Tierra, Universidad de Granada-C.S.I.C., \\ Av. Fuentenueva s/n, 18002 Granada, Spain
}

\begin{abstract}
Alteration of the crystal structure of Mulhacén antigorite caused by dry, vibration grinding was investigated by X-ray diffraction (XRD), infrared spectroscopy (IR), thermal analyses (TG), grainsize distribution, and transmission and analytical electron microscopy (TEM, AEM). Grinding for $1 \mathrm{~min}$ reduces particles to a size ideal for IR and TG. With prolonged grinding, XRD and electron diffraction patterns showed that the crystal structure was affected mainly along the $c$ axis, causing a partial loss of crystallinity. TG analyses revealed that vibration grinding modified mineral dehydration, accelerating the dehydroxylation process and transforming the structural $\mathrm{OH}$ to adsorbed water in the resulting matrix. IR spectra and AEM showed that grinding affected the tetrahedral sheet to a lesser extent than the octahedral sheet. Partial release of $\mathrm{Mg}$ by preferential destruction of the octahedral sheet after $10 \mathrm{~min}$ grinding produced an increase in the $\mathrm{Si} / \mathrm{Mg}$ ratio in semi-crystalline particles, whereas the amorphous material product after $120 \mathrm{~min}$ showed the same composition as the initial antigorite. TEM and grain-size distribution results revealed that grinding led to a general decrease in particle size at the beginning of the experiment followed by the agglomeration of ultrafine particles as grinding proceeded.
\end{abstract}

Key Words-Antigorite, Crystallinity, Dehydroxylation, Dry Grinding, IR Spectra, Serpentine, Thermal Analysis.

\section{INTRODUCTION}

Grinding is a common treatment for phyllosilicates in industrial operations, in research laboratories, and in studies related to soil genesis. Grinding affects the structure and properties of layer-silicates in various ways. The processes involved were widely researched, especially for kaolinite, montmorillonite, and mica (e.g., Halavay et al., 1977; Aglietti et al., 1986). Precise details on the degradation processes of montmorillonite by dry grinding were given by Cícel and Kranz (1981). They suggested that the exchangeable cations are affected first, then the hydroxyl groups and finally, the separation of the tetrahedral and octahedral sheets occurs. In a study on sepiolite, Cornejo and Hermosin (1988) found that the cross-linked ribbon structure of sepiolite is much more resistant to mechanical stress than the layer structure of smectite or kaolinite. Nevertheless, little is known of the behavior of serpentine to grinding. Papirer and Roland (1981), in a study on chrysotile, found that grinding in lowviscosity organic solvents leads to three successive and overlapping processes; rapid defiberization of the asbestos bundles followed by fragmentation of the isolated fibrils and, finally, amorphization and agglomeration resulting in a drastic decrease in the specific area.

The purpose of this work is to clarify the mechanically induced crystal-structure distortion of antigorite to a quasi-amorphous state using a vibration grinder. To our knowledge, this is the first comprehensive investigation on the alteration of the crystal structure of antigorite by vibration grinding.

\section{EXPERIMENTAL}

\section{Material}

The material used is a serpentinite rock from the Mulhacén group of the Sierra Nevada Complex in the Betic Cordillera (SE Spain). The mineral composition was determined by optical microscopy, X-ray diffraction (XRD), and transmission electron microscopy (TEM), and analytical electron microscopy (AEM). Antigorite was the major serpentine mineral, with small amounts of chrysotile and berthierine (detectable only by TEM). The major impurities were olivine and magnetite (both $5 \%$ ). Electron microprobe analyses (EMPA) of the Mulhacén antigorite and related chemical formulae, are shown in Table 1.

\section{Grinding procedures}

An HSM 100 vibration grinder was used for grinding. It consists of a cylindrical tungsten container (14 $\mathrm{cm}$ inner diameter) within which a tungsten ring (10 $\mathrm{cm}$ diameter) and cylinder $(8 \mathrm{~cm}$ diameter) are concentrically placed. The rock was initially ground in amounts of $400 \mathrm{~g}$ for $30 \mathrm{~s}$ to allow for suitable sample for XRD, TEM, infrared (IR) and thermal gravimetric (TG) analyses. This material was then considered as "starting" material (sample at 0 min grinding). The starting material was ground in amounts of $100 \mathrm{~g}$ for $1,10,60$, and $120 \mathrm{~min}$. After every minute of grinding the process was halted for $30 \mathrm{~s}$ to avoid overheating and after $5 \mathrm{~min}$ of grinding the process was halted for $90 \mathrm{~s}$ for the same purpose. The temperature during grinding never exceeded $60^{\circ} \mathrm{C}$. Presented data are total grinding time and do not include the "rest" time. 
Table 1. Electron-microprobe analyses of antigorite and structural formulae on the basis of five $\mathrm{O}$ and four $(\mathrm{OH})$.

\begin{tabular}{|c|c|c|c|c|c|c|c|c|c|c|}
\hline Oxides & 1 & 2 & 3 & 4 & 5 & 6 & 7 & 8 & 9 & 10 \\
\hline $\mathrm{Na}_{2} \mathrm{O}$ & 0.00 & 0.00 & 0.01 & 0.00 & 0.01 & 0.00 & 0.01 & 0.00 & 0.00 & 0.00 \\
\hline $\mathrm{MgO}$ & 39.12 & 39.00 & 39.80 & 39.30 & 39.50 & 39.10 & 39.52 & 39.40 & 39.12 & 39.68 \\
\hline $\mathrm{SiO}_{2}$ & 43.47 & 43.30 & 44.40 & 43.60 & 43.90 & 43.30 & 43.57 & 43.60 & 43.45 & 44.06 \\
\hline $\mathrm{Al}_{2} \mathrm{O}_{3}$ & 2.33 & 2.44 & 1.12 & 2.31 & 1.93 & 2.24 & 1.80 & 2.26 & 2.03 & 1.10 \\
\hline $\mathrm{K}_{2} \mathrm{O}$ & 0.01 & 0.01 & 0.01 & 0.01 & 0.01 & 0.00 & 0.00 & 0.00 & 0.01 & 0.00 \\
\hline $\mathrm{TiO}_{2}$ & 0.01 & 0.01 & 0.00 & 0.02 & 0.00 & 0.01 & 0.01 & 0.02 & 0.00 & 0.00 \\
\hline $\mathrm{Ca}_{2} \mathrm{O}$ & 0.00 & 0.01 & 0.00 & 0.01 & 0.04 & 0.00 & 0.01 & 0.00 & 0.00 & 0.00 \\
\hline $\mathrm{Cr}_{2} \mathrm{O}_{3}$ & 0.00 & 0.00 & 0.08 & 0.22 & 0.05 & 0.19 & 0.14 & 0.13 & 0.10 & 0.02 \\
\hline Feo & 2.07 & 2.16 & 2.27 & 2.13 & 2.15 & 2.18 & 2.12 & 2.14 & 2.07 & 1.94 \\
\hline $\mathrm{MnO}$ & 0.05 & 0.07 & 0.05 & 0.04 & 0.05 & 0.06 & 0.05 & 0.02 & 0,02 & 0.05 \\
\hline Total & 87.09 & 87.00 & 87.80 & 87.60 & 87.70 & 87.10 & 87.27 & 87.80 & 86.85 & 86.97 \\
\hline \multicolumn{11}{|c|}{ Number of ions on the basis of five $\mathrm{O}$ and four $(\mathrm{OH})$} \\
\hline & 1 & 2 & 3 & 4 & 5 & 6 & 7 & 8 & 9 & 10 \\
\hline $\mathrm{Si}$ & 2.01 & 2.01 & 2.04 & 2.00 & 2.02 & 2.00 & 2.01 & 2.00 & 2.01 & 2.04 \\
\hline $\mathrm{Mg}$ & 2.70 & 2.69 & 2.72 & 2.69 & 2.70 & 2.70 & 2.72 & 2.70 & 2.70 & 2.74 \\
\hline $\mathrm{Fe}$ & 0.08 & 0.08 & 0.08 & 0.08 & 0.08 & 0.08 & 0.08 & 0.08 & 0.08 & 0.07 \\
\hline $\mathrm{Al}$ & 0.12 & 0.13 & 0.06 & 0.12 & 0.10 & 0.12 & 0.09 & 0.12 & 0.11 & 0.06 \\
\hline$\Sigma(\mathrm{Mg}, \mathrm{Fe}, \mathrm{Al})$ & 2.90 & 2.90 & 2.86 & 2.89 & 2.88 & 2.90 & 2.89 & 2.90 & 2.89 & 2.87 \\
\hline
\end{tabular}

\section{Examination of the material}

An uncovered thin section was prepared for initial optical study and the electron microprobe analysis (EMPA) which followed the procedure as Nieto (1997). Powder XRD patterns were recorded on the starting and ground samples with a Philips PW-1710 diffractometer using $\mathrm{CuK} \alpha$ radiation, also following

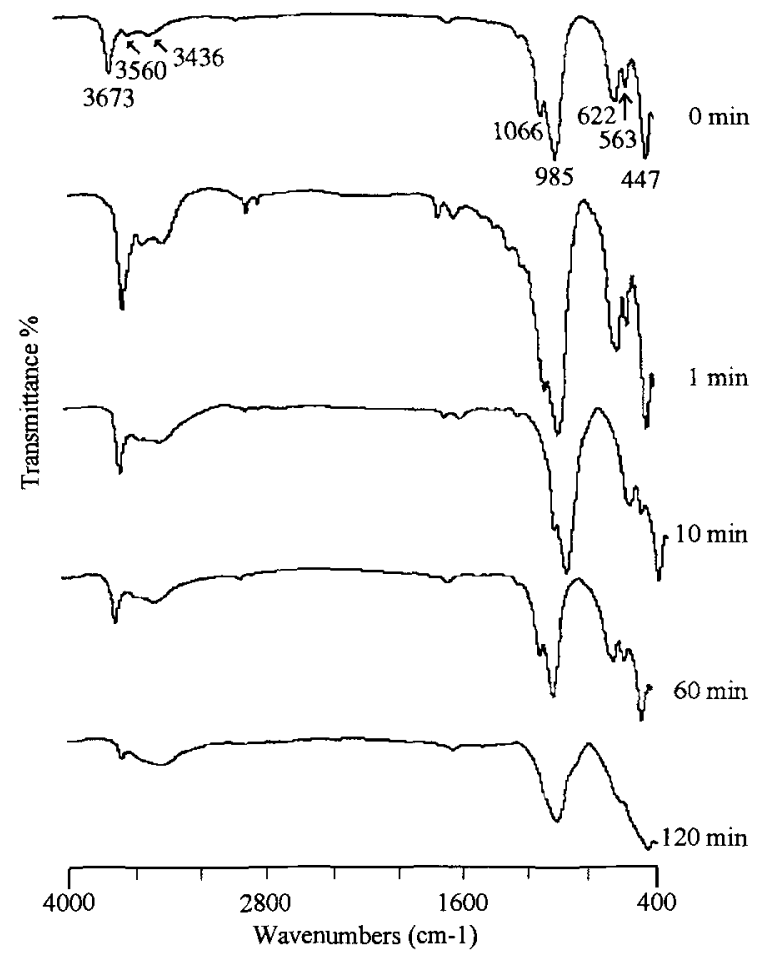

Figure 1. Infrared spectra of starting and ground antigorite for times indicated.
Nieto (1997). Determination of crystallinity values followed Kisch (1991). The IR spectra were obtained with a Nicolet 20SXB FT-IR spectrometer over the range $4000-400 \mathrm{~cm}^{-1}$ at a scanning speed of 600 $\mathrm{cm}^{-1} / \mathrm{min}$ from pressed discs using $1.0 \mathrm{mg}$ of ground sample and $800 \mathrm{mg}$ of $\mathrm{KBr}$.

For TEM and AEM analyses, material at 0,10 , and $120 \mathrm{~min}$ of grinding, was dispersed in distilled water and deposited on collodion films supported on copper grids and air-dried at room temperature. TEM images, electron diffraction patterns, and semi-quantitative analyses were obtained with a Philips CM20 instrument operated at $200 \mathrm{kV}$ at the "Centro de Instrumentación Científica" (C.I.C.) at Granada University. Experimental conditions were the same as in Sánchez-Navas et al. (1998). The AEM data (not shown) of "starting" antigorite are very close to those obtained by EMPA. Grain-size distribution of the ground samples was determined on a GLAI-CIS-1 apparatus using aqueous solution as a dispersive medium. The $\mathbf{T G}$ analyses were performed on $43 \mathrm{mg}$ of sample in a SHIMADZU TGA $-50 \mathrm{H}$ in air at a heating rate of $10^{\circ} \mathrm{C} / \mathrm{min}$.

\section{RESULTS}

\section{Infrared spectra}

Changes in the transmittance band intensities during grinding are illustrated in Figure 1. Table 2 presents the band assignments. Note that all the initial infrared bands increase in value with grinding, and become better defined between 0-1 min (Figure 1). After becoming better defined, however, the values decreased to below the initial values of the starting sample. The transmittance bands at 1066,622 , and $563 \mathrm{~cm}^{-1}$, are characteristic of the Si-O stretching vibrations with perpendicular polarization, of the $\mathrm{OH}$ deformation, 
Table 2. Transmittance bands and related group-of-atom vibrations according to $1=$ Luce (1971), $2=$ Heller-Kallai $e t$ al. (1975), 3 = Yariv and Heller-Kallai (1975), and $4=$ Wilson $(1987) . \mathrm{W}==$ Wavenumbers.

\begin{tabular}{clc}
\hline $\mathrm{W}\left(\mathrm{cm}^{-1}\right)$ & \multicolumn{1}{c}{ Attributed to } & References \\
\hline 3673 & Structural $\mathrm{OH}$ & 1 \\
3560 & Substitution of trivalent ions for $\mathrm{Mg}$ & 2 \\
3436 & Adsorbed water & 2 \\
1066 & Si-O stretching vibrations & 3 \\
& with perpendicular polarisation & 3 \\
985 & Si-O vibrations in the basal plane & 3,4 \\
622 & OH deformation & 3 \\
563 & Mg-O out-of-plane & 1 \\
447 & Si-O stretching vibrations & \\
\hline
\end{tabular}

and of the $\mathrm{Mg}-\mathrm{O}$ out-of-plane vibrations, respectively. The bands were well developed in the spectra of the sample ground for $1 \mathrm{~min}$. With prolonged grinding, the intensities of these bands decreased and after 120 min of grinding they disappeared entirely. The $\mathrm{OH}^{-}$ stretching vibration band at $3673 \mathrm{~cm}^{-1}$ and that of the Si-O vibrations in the basal plane at $985 \mathrm{~cm}^{-1}$ show a general decrease by grinding. The former is weakly present in the spectrum corresponding to $120 \mathrm{~min}$ grinding, whereas the latter is still well-defined. The band at $3436 \mathrm{~cm}^{-1}$, corresponding to adsorbed water, increases with increasing duration of grinding.

To clarify the relationship between the bands at 3673 and $3436 \mathrm{~cm}^{-1}$, the transmittance ratio $T 3436 /$ T3673 was measured as a function of time of grinding, as shown in Figure 2. Note that the ratio initially decreased slightly, but then a general increase was observed.

\section{$X$-ray study}

The degree of lattice distortion and amorphization of the samples were studied by powder XRD by comparing the Mulhacén antigorite to the patterns reported by Bailey (1980). When antigorite was ground for 1$10 \mathrm{~min}$, considerable destruction of the structure occurred, as indicated by a general decrease in the intensity of the reflections (Figure 3). Grinding for 120 min caused complete destruction of the mineral, at least along the $c$ axis, and gives rise to diffraction patterns with only a few weak $(h k l)$ reflections.

Figure 4 shows the peak-area evolution for each of the indicated reflections as a function of time of grinding. Significant differences are clear in the rate of decrease in peak area of these diffraction bands. The greatest change was observed for the $(001)$ reflection at $7.22 \AA$, which decreased in area in the first minute of grinding. The $(16,0,1)$ reflection at $2.52 \AA$ increased in area from 0 to $10 \mathrm{~min}$ of grinding and then declined to below the initial value, whereas the combined ( $83 \overline{2}$ ) and $(16,0,2)$ reflections at $2.16 \AA$ showed an intermediate behavior between the $(001)$ and $(16,0,1)$ reflections. The $d(001)$, the width at half-height, and the

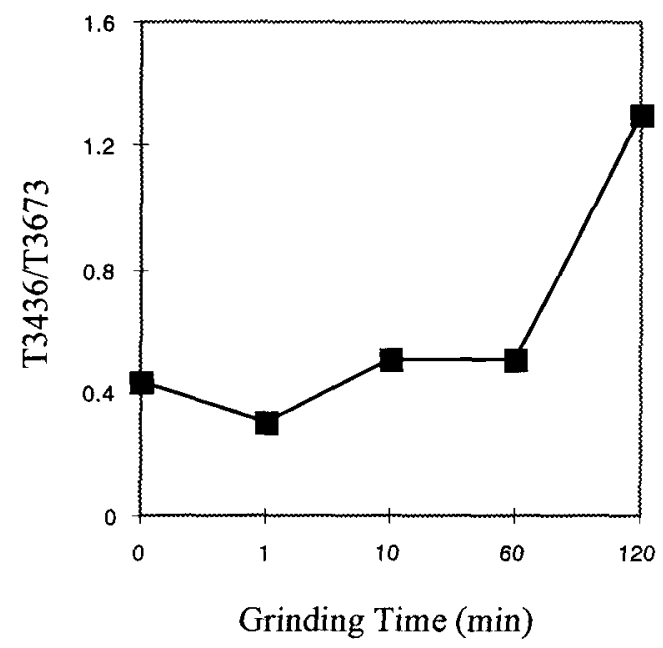

Figure 2. Changes in the transmittance ratio T3436/T3673 during grinding. Note that the scale varies for the time axis.

integral breadth (peak area/peak intensity) values as a function of grinding time are presented in Table 3. The width at half-height and the integral breadth of the basal reflections (001) and (002) increased slowly, with the $d$-values also showing a small increase.
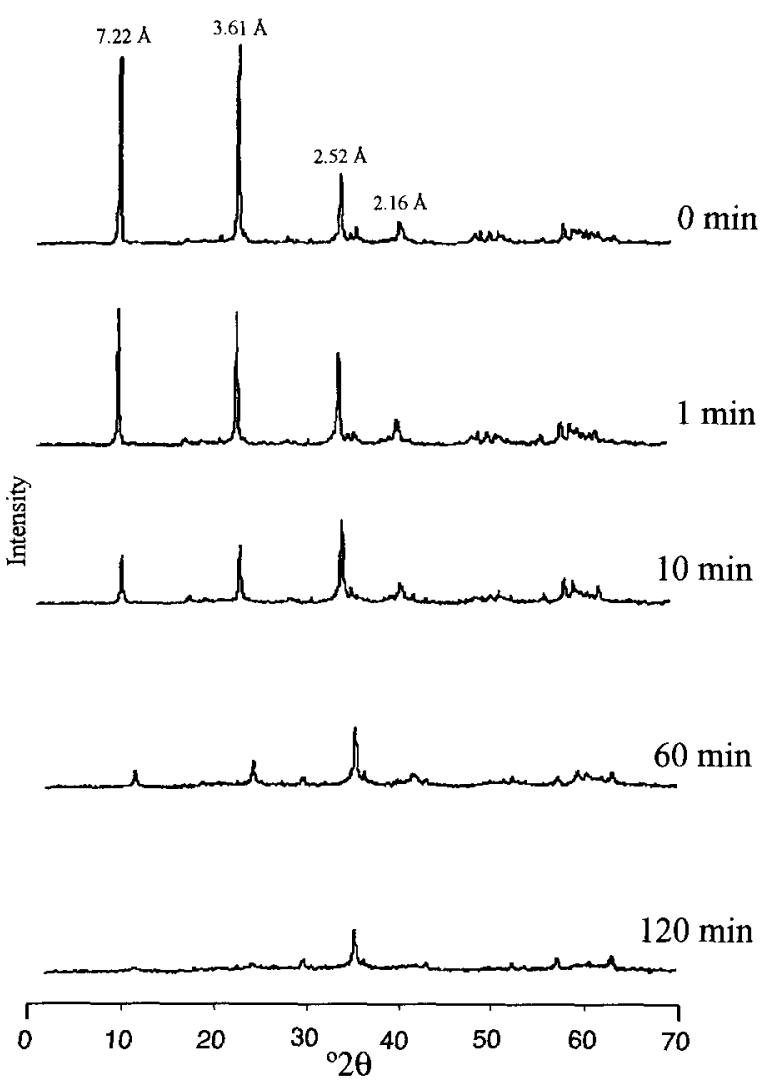

Figure 3. Powder X-ray diffractograms of starting and ground antigorite for times indicated. ( $\mathrm{CuK} \alpha$ radiation). 


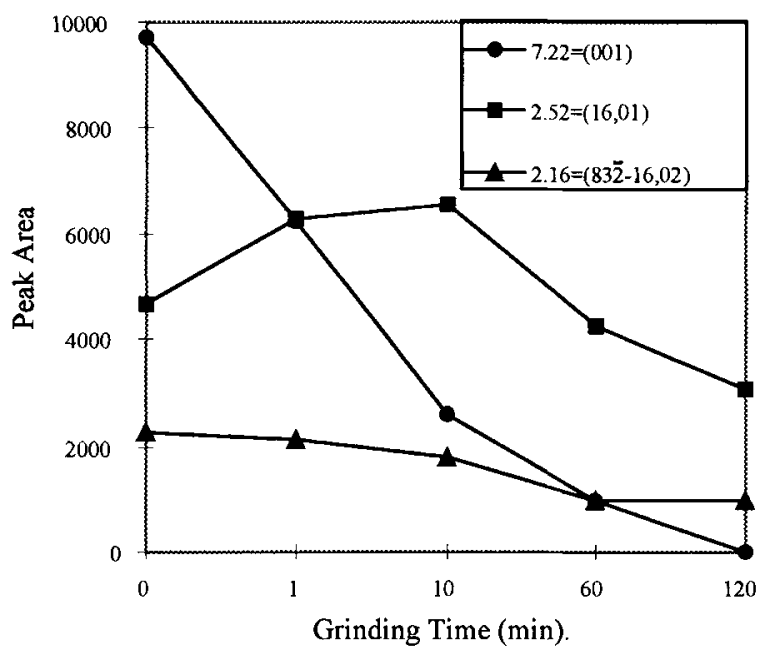

Figure 4. Changes in peak area of the basal reflection at $7.22 \AA$ and two $(h k l)$ reflections at 2.52 and $2.16 \AA$ during grinding. Note that the scale varies for the time axis.

\section{Electron microscopy}

Electron diffraction. The Mulhacén antigorite samples $(0,10$, and $120 \mathrm{~min}$ grinding) were also examined by electron diffraction. Because of the (001) cleavage, all TEM observations were made approximately perpendicular to the $(001)$ plane. Figure 5 presents electron diffraction patterns showing the effect of grinding on the structure of the mineral. The electron diffraction pattern of the starting antigorite is shown in Figure 5a, and this pattern is very similar to those by Yada (1979), Viti and Mellini (1996), and Viti (1997). After 10 min of grinding, three different materials occurred in the sample: an amorphous material with no significant pattern, a well-crystallized antigorite similar to Figure 5a (neither are shown in Figure 5), and an intermediate transitional material with diffuse rings (Figure $5 \mathrm{~b}$ ). The material ground for $120 \mathrm{~min}$ displayed an amorphous material with no significant pattern. Oc-
Table 3. The $d(001)$, the width at half height, and the integral breadth of the $(001)$ and the $(002)$ reflections during grinding. $(*)=$ not measurable.

\begin{tabular}{|c|c|c|c|c|c|}
\hline \multirow{2}{*}{$\begin{array}{l}\text { Grinding } \\
\text { time } \\
\text { (min) }\end{array}$} & \multirow[b]{2}{*}{$d(001)$} & \multicolumn{2}{|c|}{ Width at half height } & \multicolumn{2}{|c|}{ Integral breadth } \\
\hline & & (001) & $(002)$ & $(001)$ & (002) \\
\hline 0 & 7.225 & 0.18 & 0.17 & 0.26 & 0.21 \\
\hline 1 & 7.225 & 0.18 & 0.19 & 0.26 & 0.22 \\
\hline 10 & 7.237 & 0.20 & 0.21 & 0.30 & 0.25 \\
\hline 60 & 7.248 & 0.22 & 0.22 & 0.34 & 0.27 \\
\hline 120 & $* * *$ & $* * *$ & $* * *$ & $* * *$ & $* * *$ \\
\hline
\end{tabular}

casionally, particles show a diffraction ring with a spacing of $2.57 \AA$.

Transmission electron microscopy. The TEM image in Figure 6 shows an example of the particle microcrystal morphology at the final stage of grinding. This micrograph reveals that serpentinite rock alteration occurs in two steps. First, the disintegration of the primary coarser particles produces ultrafine particles with diameters of 125-200 $\AA$ (arrows in Figure 6). Second, these particles adhere to each other to form large agglomerations (large particles in Figure 6). Mechanochemical reactions, such as the transformation of structural $\mathrm{OH}$ groups to adsorbed water, increased surface energy, and the formation of the amorphous material during grinding probably play an important role.

Analytical electron microscopy. The chemical analyses of starting antigorite and that ground for 10 and 120 min were obtained by AEM. A change of composition (Figure 7) affected the two major elements ( $\mathrm{Si}$ and $\mathrm{Mg}$ ). The change is related to both the extent of grinding and the particle crystallinity (amorphous vs. semicrystalline). Particles analysed after $10 \mathrm{~min}$ of grinding (dark circles) which exhibited an electron diffraction pattern similar to Figure $5 \mathrm{~b}$ were affected by a drastic increase in the $\mathrm{Si} / \mathrm{Mg}$ ratio. In fact, there is depletion of $\mathrm{Mg}$ by preferential destruction of the octahedral sheet. Normalizing of this composition on the
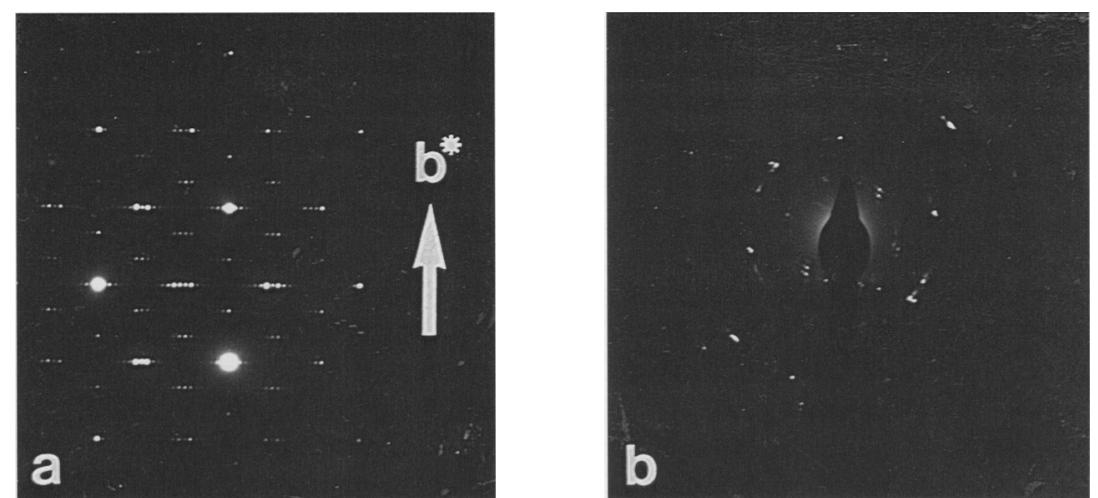

Figure 5. Changes in the electron diffraction patterns of: (a) starting antigorite in the (001) orientation, (b) semi-crystalline antigorite after $10 \mathrm{~min}$ of grinding. 


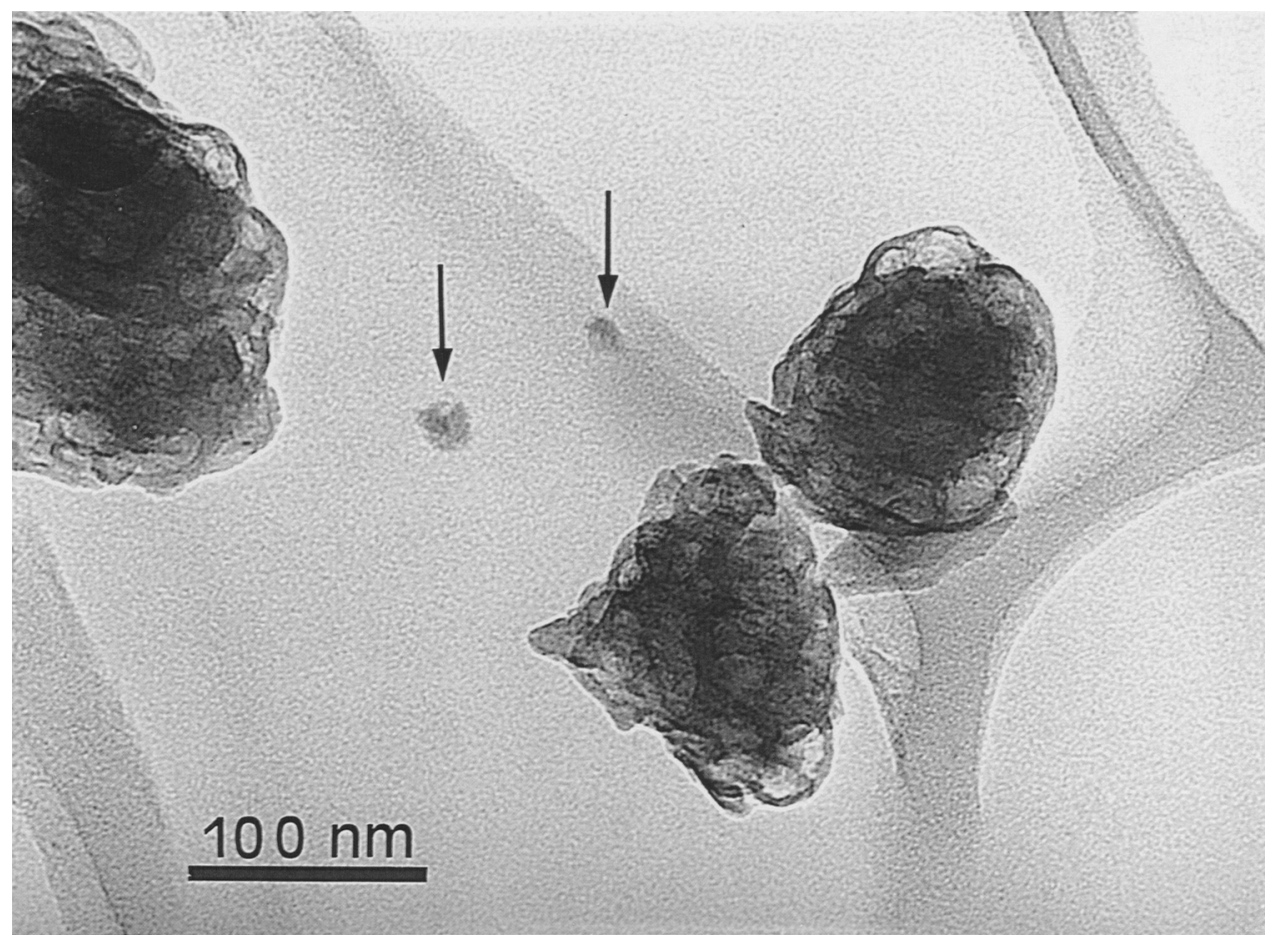

Figure 6. Transmission electron micrograph showing the external morphology of the particles at the end of grinding (120 $\min )$.

basis of five $\mathrm{O}$ atoms and four $(\mathrm{OH})$ produces $\mathrm{Si}>2$, indicating a lower negative charge, presumably related to $(\mathrm{OH})$, would be necessary to maintain the maximum possible value $(\mathrm{Si}=2)$. However, amorphous material at $120 \mathrm{~min}$ of grinding (open triangles) with no apparent diffraction by electrons nearly reproduced the composition of the initial antigorite, whereas that at 10 min of treatment (open circles) represents an intermediate.

\section{Thermal analyses}

The TG curve of the sample ground for $1 \mathrm{~min}$ shows two water losses at different temperature ranges

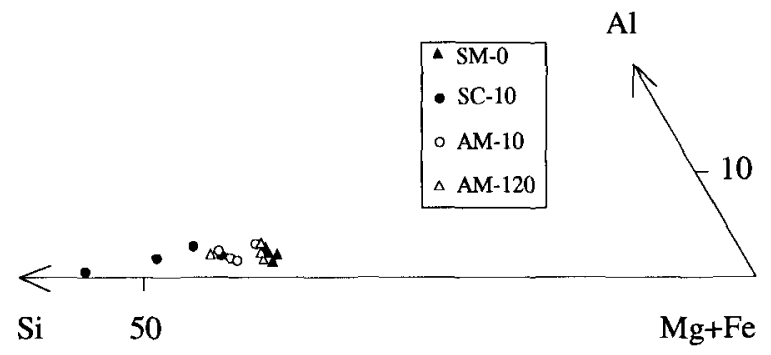

Figure 7. Representation in a ternary diagram $[\mathrm{Al}-\mathrm{Si}-(\mathrm{Mg}$ $+\mathrm{Fe})]$ of the chemical data of antigorite at different stages of degradation $(\mathrm{SM}-0=$ starting material, $\mathrm{SC}-10=$ semicrystalline particles after 10 min of grinding, AM-10 and AM-120 are amorphous materials after 10 and 120 min of grinding, respectively).
(Figure 8). The low-temperature water loss, not detected at 0 min of grinding, occurs between $0-200^{\circ} \mathrm{C}$ and represents adsorbed water (the maximum loss is at $80^{\circ} \mathrm{C}$ ). Structural water is lost between $600-800^{\circ} \mathrm{C}$, with a maximum loss occurring at $748^{\circ} \mathrm{C}$. The temperature corresponding to the maximum loss of structural $\mathrm{OH}$ decreased from $748^{\circ} \mathrm{C}$ (after $1 \mathrm{~min}$ of grinding) to $662^{\circ} \mathrm{C}$ (after $120 \mathrm{~min}$ of grinding). The TG curve of a sample after $120 \mathrm{~min}$ of grinding showed a completely different behavior, with a less marked difference between the two end-members (i.e., adsorbed water vs. structural water loss) and water loss becomes more evenly distributed. Weight loss of structural water also decreased significantly (Figure 9). In contrast, the weight loss of the adsorbed water increased (Figure 9) and the temperature corresponding to where maximum loss occurs increased from 80 to $155^{\circ} \mathrm{C}$ (Figure 8). The overall water loss increased slightly and the value corresponding to $120 \mathrm{~min}$ $(11.85 \%)$ was very close to the theoretical value for pure antigorite (Caillère et al., 1982; Viti and Mellini, 1996).

\section{Grain-size distribution}

The variation in the particle-size fractions as a function of grinding time (Table 4) shows three stages: 1) grinding for $1 \mathrm{~min}$ increases the number of $\leq 2-\mu \mathrm{m}$ particles, which reaches a maximum, and produces a relative decrease in particle sizes with diameters of 2 


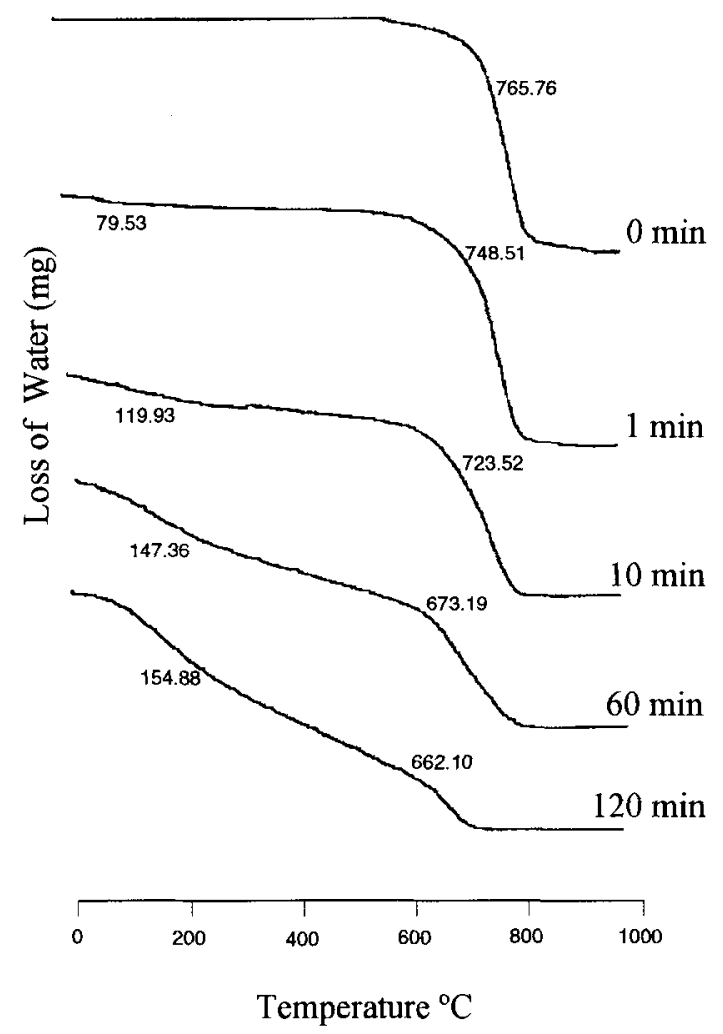

Figure 8. TG curves of starting and ground antigorite for times indicated.

$10 \mu \mathrm{m}$, as well as the elimination of $10-20-\mu \mathrm{m}$ particles; 2) grinding for $60 \mathrm{~min}$ results in a general decrease in the $\leq 2-\mu \mathrm{m}$ fraction and a relative increase in the $2-10-\mu \mathrm{m}$ fraction and a small proportion $(1.43 \%)$ of the $10-20-\mu \mathrm{m}$ size particles occurred again after $10 \mathrm{~min}$ of grinding; 3 ) at $120 \mathrm{~min}$ the $\leq 2-\mu \mathrm{m}$ size particles increased and the $2-10-\mu \mathrm{m}$ fraction decreased once again.

\section{DISCUSSION}

The degradation of the Mulhacén antigorite by a vibration grinder is described as a series of parallel changes in the crystal structure and chemistry of the mineral. The increase in band intensities evident in the IR spectra between $0-1$ min of grinding is explained by a decrease in particle size, producing an ideal IR spectrum and, therefore, increased transmittance-band intensities. Changes in the structural $\mathrm{O}-\mathrm{H}$ and the $\mathrm{Si}-$ $O$ vibrations may be used to monitor the relative resistance of the octahedral and tetrahedral sheets to grinding. The general decrease in intensity of the band at $3673 \mathrm{~cm}^{-1}$, the disappearance of bands at 622 and $563 \mathrm{~cm}^{-1}$, and the persistence of the transmittance bands at 985 and $447 \mathrm{~cm}^{-1}$ all suggest that grinding affects the tetrahedral sheet to a lesser extent than the octahedral sheet.

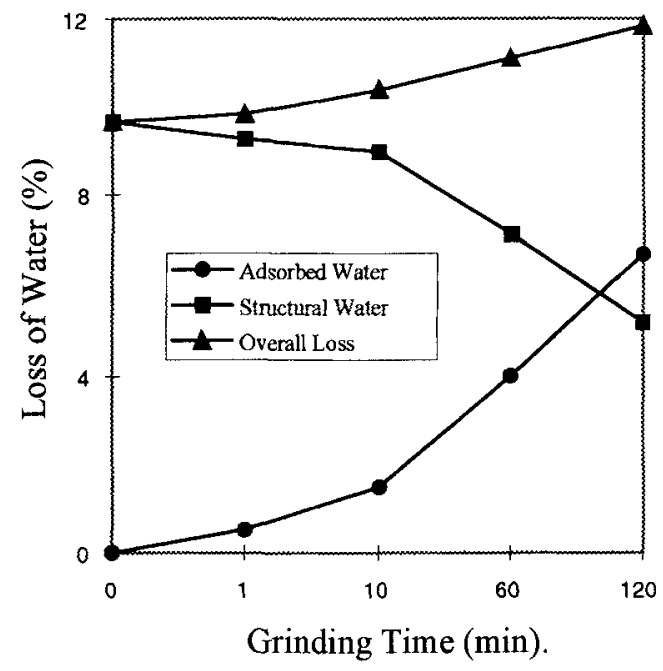

Figure 9. Loss of water during heat treatment. Note that the scale varies for the time axis.

The chemical data support the results of the IR spectra in that grinding affects the tetrahedral sheet less than the octahedral sheet; $\mathrm{Mg}$ decreases after $10 \mathrm{~min}$ of grinding, Si increases, and Al remains constant. At the end of grinding, the composition of the resulting amorphous material is quite similar to that of the fresh antigorite. This suggests that early grinding causes the decrease of $\mathrm{Mg}$ by preferential destruction of the octahedral sheet, giving rise to a relative increase of $\mathrm{Si}$ in the particles. At the end of grinding, the resulting matrix consists of $\mathrm{Mg}$ Si-rich material similar in composition to the starting antigorite and corresponding to residual tetrahedral and octahedral sheets weakly bound within the system.

In Figure 2, the T3436/T3673 transmittance ratio decreased slightly at first due to the more ideal grain size and thus to the improved band of the structural $\mathrm{O}-\mathrm{H}$ stretching vibration. The change in band characteristics at $3673 \mathrm{~cm}^{-1}$ which is related to the structural $\mathrm{O}-\mathrm{H}$ stretching vibration, and the broad band at 3436 $\mathrm{cm}^{-1}$ which is related to the randomly-attached $\mathrm{OH}$ ions and adsorbed water, is clearly related to a change in the status of the hydroxyl groups. These groups are irreversibly displaced from their structural positions during grinding and remain in the system bound either as water molecules adsorbed on the degraded matrix or as $\mathrm{OH}$ groups linked by unsaturated broken bonds.

Table 4. Grain-size evolution during grinding.

\begin{tabular}{crrrrr}
\hline \multirow{2}{*}{$\begin{array}{c}\text { Particle } \\
\text { size }(\mu \mathrm{m})\end{array}$} & \multicolumn{1}{c}{0} & \multicolumn{1}{c}{ Grinding time (min) } \\
\hline $0-2$ & 31.62 & 53.78 & \multicolumn{1}{c}{10} & \multicolumn{1}{c}{60} & \multicolumn{1}{c}{120} \\
\hline $2-10$ & 68.00 & 46.24 & 57.84 & 33.80 & \multicolumn{1}{c}{41.5} \\
$10-20$ & 0.39 & 0.00 & 1.43 & 0.00 & 0.00 \\
\hline
\end{tabular}


From Figure 8, a close relationship appears to exist between the adsorbed and the structural water, which is consistent with the conclusion of the IR results. After the dehydroxylation of the mineral by dry grinding, the OH groups remained in the system bound to the degraded matrix either in the form of $\mathrm{OH}$ groups linked by unsaturated broken bonds or as adsorbedwater molecules. The weight loss corresponding to samples after $120 \mathrm{~min}$ of grinding $(11.85 \%)$ is very close to the theoretical value of pure antigorite. Grinding seems to be an important process for water extraction, including structural water, thus accelerating the dehydroxylation process.

From the XRD results grinding in a vibration grinder disrupts the structure along the $c$ axis more than within the (001) plane, since all basal reflections do not occur after $120 \mathrm{~min}$, whereas the $(16,0,1)$ reflection is well represented even after $120 \mathrm{~min}$ of grinding. This is confirmed by both electron diffraction and IR; some particles of the material ground for $120 \mathrm{~min}$ showed a diffuse ring at $2.57 \AA$, whereas the band at $1066 \mathrm{~cm}^{-1}$, assigned to the $\mathrm{Si}-\mathrm{O}$ stretching vibration with perpendicular polarization, did not occur. The general increase of the width at half-height and the integral breadth of the $(001)$ and $(002)$ reflections and the $d(001)$-values throughout grinding suggest that the vibration grinding destroys the crystal-structure of the mineral before complete amorphization. The structure of the semicrystalline particles differs from the starting material by forming "islands" in the octahedral sheet as a result of $\mathrm{Mg}$ and $\mathrm{OH}$ loss. $\mathrm{Mg}$ loss is obvious from the AEM results whereas the $\mathrm{OH}$ loss is expected to compensate the loss of positive charge from the octahedral sheet. Moreover, $\mathrm{OH}$ loss is also apparent from the IR (progressive increase in the transmittance ratio T3436/T3673) and TG (decrease in percentage of the structural-water loss) results. Although the octahedral "islands" produce faults in the periodicity of the layer stacking ( $c$ axis), the (001) plane would be maintained by the strong bonds existing between the Si tetrahedra.

In studies on kaolins, Juhász (1980) and Gonzales et al. (1991) found the specific surface area to increase initially upon grinding and to decrease as grinding continues. Papirer and Roland (1981), Henmi and Yoshinaga (1981), Cornejo and Hermosín (1988), and Pérez Rodriguez et al. (1988) reported similar behavior in chrysotile, imogolite, sepiolite, and pyrophyllite, respectively. Juhász (1980) referred to the increase in specific surface area as the "degree of dispersivity" and its decrease the "formation of aggregates by the compaction of the fine particles."

Combining TEM and grain-size results shows that dispersion and the breaking of coarser particles produces smaller but more numerous particles that produce high transmittance-band intensities in IR spectra. With continued grinding, the ultrafine particles tend to adhere to each other. Due to the increased surface en ergy, the action of the amorphous material, and probably the water adsorbed in the matrix formed by grinding (as indicated by the IR spectra and TG curves), larger agglomerates are formed.

\section{ACKNOWLEDGMENTS}

We thank N. Velilla Sánchez for the sample and geologic information and $\mathrm{C}$. Viti for helpful discussions and ideas. We are grateful to the anonymous referees for a critical review of the manuscript and the editors, W.H. Hudnall and S. Guggenheim for their valuable comments on the manuscript. The help of the following technicians was fundamental for the present work: M.M. Abad-Ortega (TEM-AEM), B. Funes (IR-Granulometry), M.A. Hidalgo-Laguna (EMPA), A. Molina-Illescas (photographic laboratory), I. Nieto (preparation of samples), M.A. Salas (TG), and P. Sánchez-Gomez (XRD). Financial support was supplied by Research Project PB961383 of the Spanish Ministry of Education and Research Group RNM-0179 of the Junta de Andalucía. We are grateful to $\mathrm{C}$. Laurin for reviewing the text and improving the English.

\section{REFERENCES}

Aglietti, E.F., Porto Lopez, J.M., and Pereira, E. (1986) Mechanochemical effects in kaolinite grinding. International Journal of Mineral Processing, 16, 125-146.

Bailey, S.W. (1980) Structures of layer silicates. In Crystal Structure of Clay Minerals and Their $X$-ray Identification, G.W. Brindley and G. Brown, eds., Mineralogical Society, London, 1-123.

Caillère, S., Hénin, S., and Rautureau, M. (1982) Minéralogie des argiles: II. Classification et nomenclature. Masson, Paris, $189 \mathrm{pp}$.

Cícel, B. and Kranz, G. (1981) Mechanism of montmorillonite structure degradation by percussive grinding. Clay Minerals, 16, 151-162.

Cornejo, J. and Hermosín, M.C. (1988) Structural alteration of sepiolite by dry grinding. Clay Minerals, 2, 391-398.

González, G.F., Ruiz Abrio, M.T., and González, R.M. (1991) Effects of dry grinding on two kaolins of different degrees of crystallinity. Clay Minerals, 26, 549-565.

Halavay, J., Jónás, K., Elek, S., and Inczédy, J. (1977) Characterisation of the particle size and the crystallinity of certain minerals by infrared spectrophotometry and other instrumental methods: I. Investigation of clay minerals. Clays and Clay Minerals, 25, 451-456.

Heller-Kallai, L., Yariv, S., and Gras, S. (1975). Hydroxyl stretching frequencies of serpentine minerals. Mineralogical Magazine, 40, 197-200.

Henmi, T. and Yoshinaga, N. (1981) Alteration of imogolite by dry grinding. Clay Minerals, 16, 139-149.

Juhász, A.Z. (1980) Mechano-chemical activation of kaolin minerals. Acta Mineralogica-Petrographica, 24, 121-145.

Kisch, H.J. (1991) Illite crystallinity: Recommendations on sample preparation, X-ray diffraction settings and interlaboratory samples. Journal of Metamorphic Geology, 9, $665-670$.

Luce, R.W. (1971) Identification of serpentine varieties by infrared absorption. US Geological Survey Professional Paper, 750B, 199-201.

Nieto, F. (1997) Chemical composition of metapelitic chlorites: X-ray diffraction and optical property approach. $E u$ ropean Journal of Mineralogy, 9, 829-841. 
Papirer, E. and Roland, P. (1981). Grinding of chrysotile in hydrocarbons, alcohol and water. Clays and Clay Minerals, 29, 161-170.

Pérez-Rodríguez, J.L., Madrid, L., and Sánchez-Soto, P.J. (1988) Effects of dry grinding on pyrophyllite. Clay Minerals, 23, 399-410.

Sánchez-Navas, A., Martín-Algarra, A., and Nieto, F. (1998) Bacterially-mediated authigenesis of clays in phosphate stromatolites. Sedimentology, 45, 519-533.

Viti, C. (1997) Electron diffraction patterns of natural antigorites: A still unknown modulated crystal structure. In Electron Crystallography, D.L. Dorset, S. Hovmöller, and X.D. Zoo, eds., Kluwer Academic Publishers, The Netherlands, 419-422.
Viti, C. and Mellini, M. (1996) Vein antigorites from Elba Island, Italy. European Joumal of Mineralogy, 8, 423-434.

Wilson, M.J. (1987) A Hand Book of Determinative Methods in Clay Mineralogy. Blackie, London, $308 \mathrm{pp}$.

Yada, K. (1979) Microstructures of chrysotile and antigorite by high resolution electron microscopy. Canadian Mineralogist, 17, 679-691.

Yariv, S, and Heller-Kallai, L. (1975) The relationship between the IR spectra of serpentines and their structures. Clays and Clay Minerals, 23, 145-152.

(Received 24 June 1998; accepted 10 December 1998; Ms. 98-082) 